\title{
MAPPING THE TOPOGRAPHY AND LAND COVER OF SABLE ISLAND
}

\section{DAVID COLVILLE ${ }^{1 *}$, BRITTANY REEVES $^{1}$, DARIEN URE ${ }^{2}$, BILL LIVINGSTONE $^{1}$, and HEATHER STEWART ${ }^{2}$}

${ }^{I}$ Applied Geomatics Research Group (AGRG), NSCC, Middleton, NS Canada

${ }^{2}$ Sable Island National Park Reserve, Parks Canada, Halifax, NS Canada

\begin{abstract}
In September 2014 the Applied Geomatics Research Group (AGRG) completed a third aerial mapping campaign of Sable Island. The AGRG first mapped the island in October 2002 with an aerial photography survey. Then in August 2009 AGRG conducted an aerial photography and Light Detection And Ranging (LiDAR) survey. Five years later these same technologies were deployed again. Each of these surveys led to an orthophoto mosaic of the island and a mapping of the land cover. The 2009 and 2014 surveys also mapped the island's topography using Digital Surface Models (DSMs) derived from the LiDAR data. Ground-truthing efforts associated with each survey provided data to assist with the interpretation and validation of the results.

The repeat surveys resulted in an excellent opportunity to quantify the topographic and land cover changes that have occurred on the island. The mapped results provide a comparison of how and where these changes have occurred over the years. AGRG is working with Parks Canada to better understand how the topography and land cover are changing. This understanding will contribute to Parks Canada Ecological Integrity monitoring program for Sable Island and inform the management planning process for one of Canada's newest national parks.

Key Words: Sable Island, LiDAR, orthophotos, landscape change, Ecological Integrity monitoring
\end{abstract}

\section{INTRODUCTION}

Sable Island is a long $(\sim 50 \mathrm{~km})$, thin $(<1.5 \mathrm{~km})$ sand dune located $\sim 350 \mathrm{~km}$ southeast of Halifax, Nova Scotia. It is a semi-vegetated $(\sim 50 \%)$ island with low $(<1.5 \mathrm{~m})$ grassland and heath communities. Sable Island's dunes represent one of the largest dune systems in

* Author to whom correspondence should be addressed: david.colville@nscc.ca 
Eastern Canada and act as essential barriers preventing the ocean from inundating the low heath and freshwater ponds in the island's interior (Byrne et al. 2014). The island is highly susceptible to erosion by wind and water because of its low topography, unstable sand substrate, and large areas of terrain without vegetation (Freedman 2001). Blow-outs and wash-overs are prevalent along both the north and south sides of the island and more frequent towards the east and west tips (Byrne et al. 2014). In general, the key factors that influence stability of the island and dune dynamics include sea level rise, erosion, island size and elevation, vegetated area, storm frequency, and the associated development of blow-outs and wash-over areas. As a result, there is a need to better understand these factors in order to track long-term changes in island topography and dune dynamics on Sable Island.

Acritical component of Sable Island's stability is the vegetation cover. The island's naturally stabilized topographic features are dependent on the sand-anchoring properties of the vegetation, where there is an expected successional continuum from colonizing and dune-forming marram grassland communities to more stable and diverse health communities, similar to other coastal and dune ecosystems (Welsh 1975, Catling et al. 1984, Freedman et al. 2014). Additionally, the vegetative cover plays a critical role in supporting biodiversity and ecological processes on the island. As a result, there is a need to monitor the extent and distribution of vegetation communities at a landscape-scale to determine how they are changing over time.

There have been several studies involving land cover classifications and assessment of the proportion of vegetated area on Sable Island in previous years. Through low altitude aerial photography and ground-truthing, Stobo and McLaren (1975) and Welsh (1975) mapped the distribution of vegetation classes and determined the total vegetated area on the island in 1972. Catling et al.(1984) mapped and described eight plant communities on the island based on interpretation of aerial photographs from 1981. Freedman (2001) examined aerial photographs from 1963, 1972, 1981, and 1996 and manually assessed changes in six cover classes over the time series. The data from Freedman (2001) are considered to be most comparable since these estimates of land cover over the four aerial survey years were completed by a single interpreter.

The topography and land cover of Sable Island have been monitored since 2002 by the Applied Geomatics Research Group (AGRG) of 
the Nova Scotia Community College (AGRG 2011, AGRG 2015). In addition to aerial photo collections used to create island-wide orthophotos, AGRG has also completed two LiDAR surveys (in 2009 and 2014) which provide high-resolution topographic mapping of the entire island. Each of AGRG's surveys has included a field survey component to collect in situ measurements and photographs of the topographic and land cover conditions. The 2014 survey also included the collection of aerial photos acquired using an Unmanned Aerial Vehicle (UAV). These photos, collected from altitudes of 5 $\mathrm{m}$ to $90 \mathrm{~m}$, were used to provide a photographic bridge between the aerial photos and the ground-based photos. They were particularly useful for validating the land cover classifications derived from the orthophotos.

Both Freedman (2001) and AGRG have completed land cover classifications using a similar set of classes. However, while Freedman (2001) focused on quantifying the size of each land cover class, AGRG has focused on high-resolution mapping from which a number of topographic and land cover products have been derived. These products provide information on the topographic and land cover changes occurring on Sable Island including: coastline delineation; island length, width, area, and volume; net loss and net gain in elevation classes; land cover classification; net loss and net gain of the land cover. AGRG and Parks Canada have been working together to identify specific Ecological Integrity (EI) measures, and to develop the monitoring frameworks and associated protocols to assess landscape change in coastal ecosystems on Sable Island.

\section{METHODS}

\section{Aerial and Field Surveys}

AGRG has conducted aerial surveys of Sable Island in 2002, 2009, and 2014. All surveys were flown at altitudes between $1200 \mathrm{~m}$ and $1400 \mathrm{~m}$, and all flight lines were designed to ensure sufficient forward and side overlap of aerial photo coverage for stereo-image processing. However, there were variations in the sensors employed (see Table 1) and the field data collected. During the 2002 survey, 332 aerial photos were acquired using a digital single-lens reflex camera with a Red Green Blue (RGB) lens. Fieldwork resulted in the collection of GPS locations for 50 ground targets that were deployed across the 
Table 1 Sensor specifications of AGRG's aerial surveys of Sable Island

\begin{tabular}{|c|c|c|c|c|}
\hline $\begin{array}{l}\text { Survey } \\
\text { Date }\end{array}$ & $\begin{array}{l}\text { LiDA } \\
\text { Sensor }\end{array}$ & $\begin{array}{l}\text { LiDAR } \\
\text { Data }\end{array}$ & $\begin{array}{l}\text { Camera } \\
\text { Sensor }\end{array}$ & $\begin{array}{l}\text { Camera } \\
\text { Data }\end{array}$ \\
\hline 4 October 2002 & NA & NA & $\begin{array}{l}\text { Canon } \\
\text { EOS 10D }\end{array}$ & $\begin{array}{l}\text { RGB } \\
(50 \mathrm{~cm} \text { res })\end{array}$ \\
\hline 15 August 2009 & $\begin{array}{l}\text { Optech } \\
\text { ALTM 3100-C }\end{array}$ & $\begin{array}{l}\sim 1.8 \text { points } / \mathrm{m}^{2} \\
(1 \mathrm{~m} \text { res } \mathrm{DSM})\end{array}$ & $\begin{array}{l}\text { Rollei } \\
\text { ACI }\end{array}$ & $\begin{array}{l}\text { RGB } \\
(13 \mathrm{~cm} \mathrm{res})\end{array}$ \\
\hline 24 September 2014 & $\begin{array}{l}\text { AHAB } \\
\text { Chiroptera }\end{array}$ & $\begin{array}{l}\sim 1.65 \text { points } / \mathrm{m}^{2} \\
(1 \mathrm{~m} \text { res DSM })\end{array}$ & $\begin{array}{l}\text { Leica } \\
\text { RCD30 }\end{array}$ & $\begin{array}{l}\text { RGB \& CIR } \\
(15 \mathrm{~cm} \text { res })\end{array}$ \\
\hline
\end{tabular}

island and visible in the photos. In 2003 fieldwork was conducted to collect Real-Time Kinematic (RTK) GPS locations and associated information on the land cover. The 2009 survey employed both LiDAR and camera sensors. Coincidently, RTK GPS was used to collect ground heights and vegetation locations along 16 approximately evenly-spaced transects across the island. A year later, 211 $2 \mathrm{~m}^{2}$ vegetation plots were sampled (Muise 2012). A $2 \mathrm{~m}^{2}$ plot frame was laid on the ground. Two RTK GPS points were taken per plot, one in the north-east and another in the south-west inside plot corners. A nadir-viewing photo (captured with a Ricoh GX200 RGB camera $\sim 2.5 \mathrm{~m}$ above the plot centre) was taken to record the vegetated details of the plot. Additionally, N/E/S/W facing photos were taken to record the landscape setting of each plot. The 2014 survey also employed LiDAR and camera sensors to produce LiDAR data comparable to the 2009 survey and both RGB and Colour Infrared (CIR) photography. During this survey, $1102 \mathrm{~m}^{2}$ vegetation plots were collected using a sampling protocol similar to what was used in 2010 (Muise 2012). Additionally, a sketch replicating the plot was drawn in the field displaying the location of species in the plot, as well as notes such as vegetation height, percent cover, and percent of each species. Also new to the 2014 fieldwork was the use of an UAV (a DJI Phantom 2 Vision+ with an RGB sensor) which was used to collect photos over a variety of areas across the island. These field-sampled data were used to assist with the topographic interpretation, the vegetation classification process, and the validation of the 2014 survey.

\section{Primary Data Layer Processing}

The photography and LiDAR datasets collected during the three surveys were used to process a set of primary data layers, specifically, orthophoto mosaics for each year and a LiDAR-derived Digital Sur- 
face Model (DSM) for 2009 and 2014. A $50 \mathrm{~cm}$ horizontal resolution orthophoto was assembled from the 2002 photos and associated GPS data. A $1 \mathrm{~m}$ horizontal resolution DSM was derived from the 2009 LiDAR data, and the aerial photography was used to create a $13 \mathrm{~cm}$ horizontal resolution orthophoto of the island. The 2014 data also resulted in a LiDAR-derived, $1 \mathrm{~m}$ horizontal resolution DSM and 15 $\mathrm{cm}$ horizontal resolution orthophotos of both the RGB and CIR aerial photography.

The data collected during the field surveys were assembled into the following databases:

- 2002 ground target GPS locations;

- 2003 RTK GPS transect locations with associated land cover;

- 2009RTK GPS transect locations with associated ground/vegetation heights and land cover;

- 2010 and $20142 \mathrm{~m}^{2}$ vegetation plots with nadir and N/E/S/W photos, plot sketches, and notes;

- 2014 UAV images processed to remove image-warp introduced by the camera and to add georeferencing.

\section{Topographic and Land Cover Product Processing}

The DSMs and orthophotos were subsequently processed to create a suite of derived products. The Esri ArcGIS v10.3 software was used in the production of both topographic and land cover data layers. Topographic products created from the DSMs include:

(i) island coastlines;

(ii) surface volumes and elevation difference models;

(ii) potential impact of sea level rise models.

Land cover products created from the orthophotos include:

(i) Normalized Difference Vegetation Index (NDVI) from the 2014 CIR orthophoto;

(ii) land cover classifications;

(iii) early (grassland and sandwort communities) and late (heath communities) succession vegetation community delineation;

(iv) net gain and net loss for major land cover classes between survey years;

(v) pond delineations. 
The island coastline for 2002 was manually delineated from the 2002 orthophoto; however, the 2009 and 2014 coastlines were derived by extracting the mean sea level $(0 \mathrm{~m})$ contour from the respective DSMs. These coastlines were then used to calculate the maximum lengths, widths, and total areas of the island. Surface volumes were calculated from the DSMs by measuring the island above five heights (i.e., $0 \mathrm{~m}, 5 \mathrm{~m}, 10 \mathrm{~m}, 15 \mathrm{~m}, 20 \mathrm{~m}$, and $25 \mathrm{~m}$ ). The elevation differences, or topographic changes, occurring between 2009 and 2014 were also measured using the DSMs. The net gain and net loss was calculated, quantified, and mapped for the entire island. The potential impacts of sea level rise were calculated by implementing flood models using the DSMs. Five heights of sea level rise (i.e., $0.5 \mathrm{~m}, 1.0 \mathrm{~m}, 1.5 \mathrm{~m}, 2.0 \mathrm{~m}$, and $2.5 \mathrm{~m}$ ) were used to map the areas that would have been flooded.

While there was an RGB orthophoto for each survey year, colour infrared photos were only collected in 2014 and thus there is only one CIR orthophoto. This was used to calculate an NDVI layer for 2014. The 2002 and 2009 orthophotos had previously been used to create a land cover map of the island, including the production of an automated land cover classification (Muise 2012). However, to control for consistency in interpretation, three new land cover maps were manually interpreted by the same individual from the orthophotos derived from each survey. The orthophotos were displayed on screen at a 1:1200 scale and land cover classes adapted from Catling, et al. (1984) were delineated. The land cover for 2014 was completed first and the availability of the NDVI results were beneficial, particularly when differentiating between sand and sparse grassland. Land cover results for 2009 and then 2002 were then derived. For each survey year the land cover classes were combined to represent early and late succession classes and these were used to compute the net gain and net loss of vegetation over the twelve year period. Ponds on the island were manually delineated from the orthophotos, as well, and changes in their surface area over the years were also measured.

\section{Validation Processing}

The fieldwork data collected were used to conduct a validation of both the resulting DSMs and land cover classifications. In 2014, the RTK GPS positions collected were corrected to the High Precision Network (HPN) base station established on the island by the Province (Bond, 2016). Then the positions were used to compare to the height values at the same locations on the DSM. This was the main validation 
procedure conducted for the topographic data. The expected accuracy of the LiDAR data, and thus the DSM heights, was within $20 \mathrm{~cm}$ of the actual heights. Cases where the RTK GPS heights were within 20 $\mathrm{cm}$ of the corresponding DSM heights were considered to be a match (although the fit within $10 \mathrm{~cm}$ was also calculated).

The land cover validation was conducted by making comparisons between the $2 \mathrm{~m}^{2}$ vegetation plot data, the UAV image data, and the island-wide land cover results. To do this, the nadir plot photos and the UAV images had to be classified into the same set of classes used for the island-wide orthophotos. The same person who had classified the 2014, 2009, and 2002 orthophotos also classified the 110 plot and $40 \mathrm{UAV}$ images, to maintain interpreter consistency. The georeferenced UAV images had horizontal resolutions between $3 \mathrm{~cm}$ and $6 \mathrm{~cm}$, while the georeferenced plot images had sub-centimetre resolution. Despite the increased resolutions, the classification was conducted using a similar procedure to that of the island-wide orthophotos: display the images at a 1:1200 scale; delineated the areas representing each land cover class; encode each area with a class code. Once this was completed, the plot results were overlaid with the UAV results and the plot and UAV results were overlaid with the island-wide results. The overlapping match of classes was then calculated to determine the fit.

\section{RESULTS AND DISCUSSION}

\section{Topography}

The dune topography of Sable Island ranges from flat, to varied, to elevated. The South Beach is a good example of an expansive, flat area on the island. The Main Station area typifies a varied topography of the island (as seen in Fig 1) and has a number of ponds nearby. The Bald Dune area represents one of the large dunes on the island without vegetation (as seen in Fig 2) with an elevation reaching over $28 \mathrm{~m}$. The area surrounding Main Station and Bald Dune are featured in Fig 3 to 15 as representative sections of the island; thereby providing a more detailed view of sections of the resulting map products.

The LiDAR-derived digital surface models provided 1 m horizontal resolution detail of the topography of Sable Island for 2009 (Fig 3) and 2014 (Fig 4). From these DSMs, coastlines were derived and from the coastlines, the lengths, widths, total areas, and volumes were derived (Tables 2 and 3). The 2002 coastline was interpreted from the 


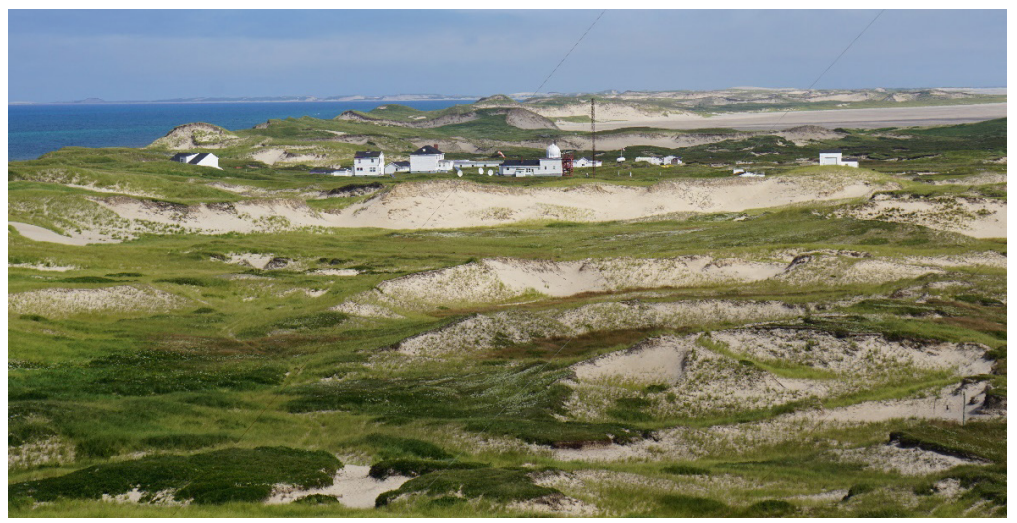

Fig 1 Main Station area - photographed from West Light looking east (by D. Colville, September 2014).

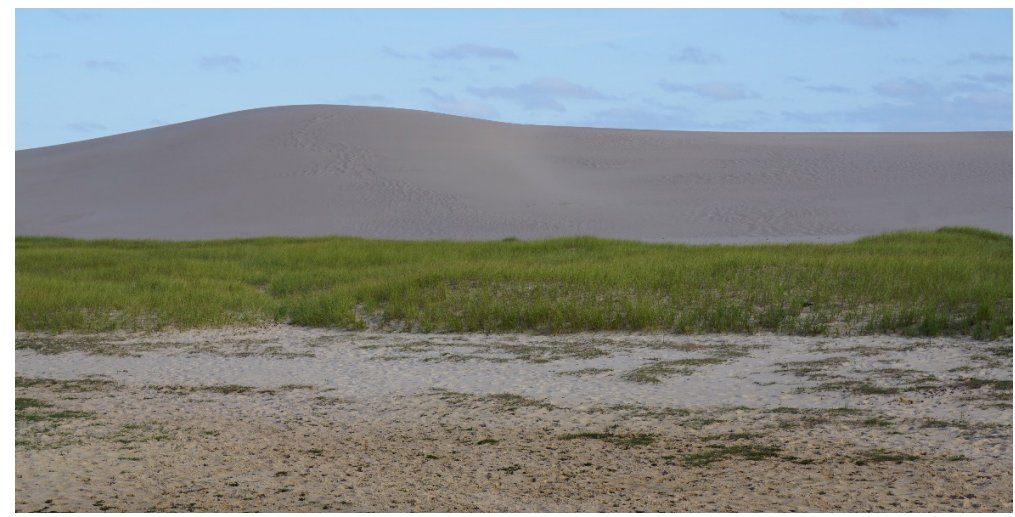

Fig 2 Bald Dune area - photographed from the north side of the dune looking south (by D. Colville, September 2014).

orthophoto given the absence of LiDAR for that survey. While the width of the island has remained relatively similar from one survey to the next, the length and volume have continued to increase and the total area has decreased, albeit very slightly. The increase in length is particularly pronounced in the eastward extension of the island. In the winter of 2014 the East Spit experienced a wash-over event which separated the eastern tip from the rest of the island. Despite this, the calculated 2014 length and area are based on a connected condition (the main portion of the island had a length of $44.69 \mathrm{~km}$ and an area of $2,878.77$ ha at the time of the survey). While the length 


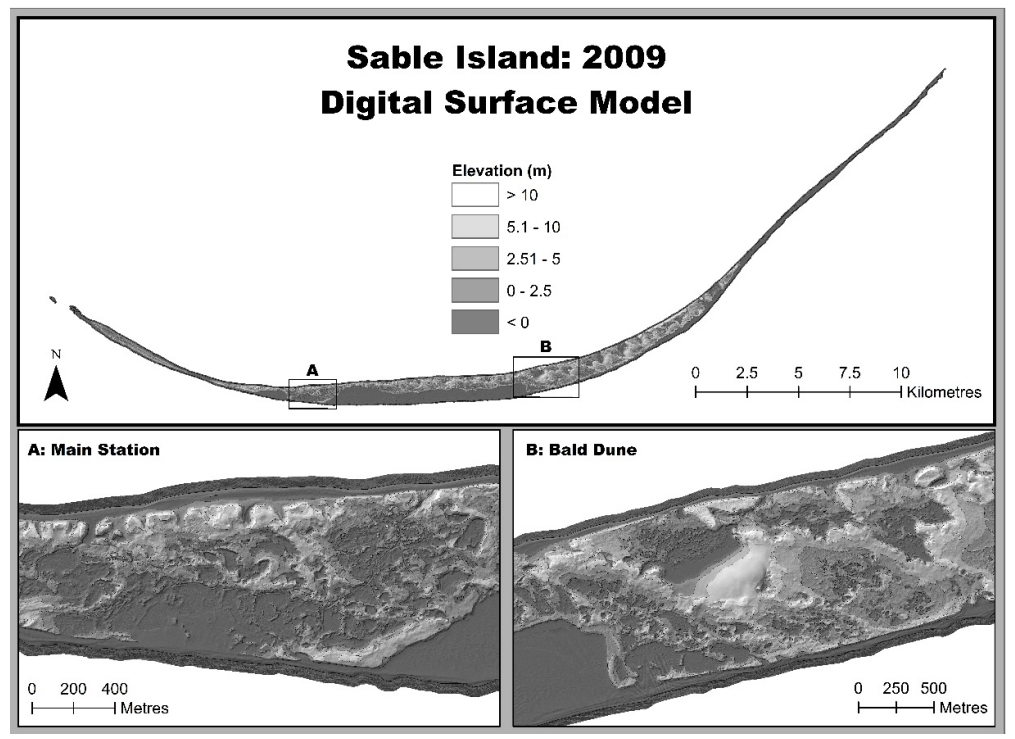

Fig 32009 LiDAR-derived Digital Surface Model of Sable Island.

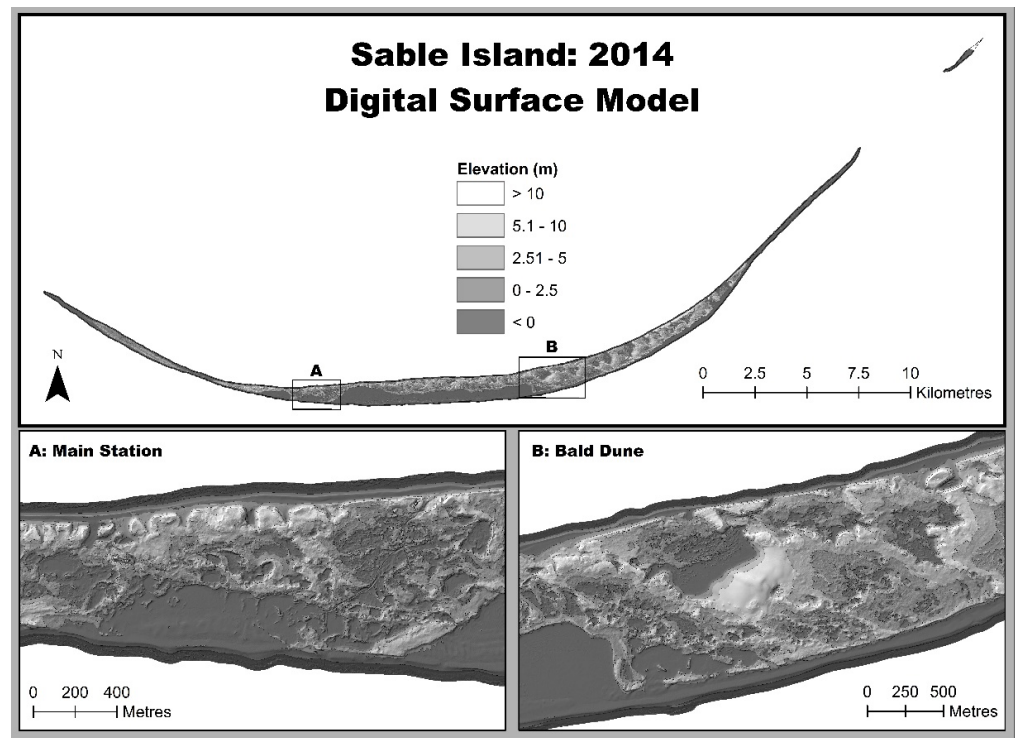

Fig 42014 LiDAR-derived Digital Surface Model of Sable Island. 
Table 2 Island length, width, area, and volume as observed each survey date

\begin{tabular}{lcccc}
\hline $\begin{array}{l}\text { Survey } \\
\text { Year }\end{array}$ & $\begin{array}{c}\text { Length } \\
(\mathbf{k m})\end{array}$ & $\begin{array}{c}\text { Width } \\
(\mathbf{k m})\end{array}$ & $\begin{array}{c}\text { Area } \\
(\mathbf{h a})\end{array}$ & $\begin{array}{c}\text { Volume } \\
\text { above } \mathbf{0 m}\left(\mathbf{m}^{3}\right)\end{array}$ \\
\hline 2002 & 48.18 & 1.28 & $3,054.78$ & NA \\
2009 & 50.01 & 1.25 & $2,979.20$ & $118,198,947.37$ \\
2014 & $52.74^{* 1}$ & 1.28 & $2,950.84^{* 2}$ & $120,765,379.81$ \\
\hline
\end{tabular}

${ }^{* 1}$ Post wash-over island length: $44.69 \mathrm{~km}$

${ }^{* 2}$ Post wash-over island area: 2,878.77ha

Table 3 Volumes above specified heights as observed from the two LiDAR surveys

\begin{tabular}{lcccccc}
\hline $\begin{array}{l}\text { Survey } \\
\text { Year }\end{array}$ & $\begin{array}{c}\text { Volume } \\
\text { above } \\
\mathbf{0 m}(\boldsymbol{\%})\end{array}$ & $\begin{array}{c}\text { Volume } \\
\text { above } \\
\mathbf{5 m}(\boldsymbol{\%})\end{array}$ & $\begin{array}{c}\text { Volume } \\
\text { above } \\
\mathbf{1 0 m}(\boldsymbol{\%})\end{array}$ & $\begin{array}{c}\text { Volume } \\
\text { above } \\
\mathbf{1 5 m}(\boldsymbol{\%})\end{array}$ & $\begin{array}{c}\text { Volume } \\
\text { above } \\
\mathbf{2 0 m}(\boldsymbol{\%})\end{array}$ & $\begin{array}{c}\text { Volume } \\
\text { above } \\
\mathbf{2 5 m}(\boldsymbol{\%})\end{array}$ \\
\hline 2009 & 100 & 28.15 & 7.57 & 1.73 & 0.25 & 0.01 \\
2014 & 100 & 28.74 & 7.92 & 1.88 & 0.32 & 0.02 \\
\hline
\end{tabular}

continued to increase, the area decreased which suggests that sections of the island continue to be shaved from the island and displaced to the east. The volume measurements indicate that there has been an increase in overall volume from 2009 to 2014 and this increase is noted in each elevation class, although the increase per class was small (less than 1\%).

Comparison of the 2009 and 2014 DSMs resulted in a determination of the net loss and net gain of the island's topography over this period (Fig 5). These topographic changes illustrate an eastward shift over time as seen by the movement of Bald Dune. Table 4 further illustrates that the island's topography has experienced considerably more elevation gain than loss across the island during the five years, consistent with the demonstrated increase in island volume during this time. Changes in the topography can also be observed in the results of the sea level rise analyses (Fig 6 and 7). The coastline south of the Main Station area increased in elevation between 2009 and 2014, thus impacting the amount of area that would be flooded if water levels had increased by $2 \mathrm{~m}$.

\section{Land Cover}

The orthophotos derived from the 2002, 2009, and 2014 surveys (Fig 8, 9, and 10, respectively) illustrate the mosaic of vegetated and non-vegetated conditions on the island at these three times. These orthophotos and the 2014 Normalized Difference Vegetation 
Table 4 Topographic net gain and net loss occurring between 2009 and 2014

\begin{tabular}{lccc}
\hline & Elevation Class $(\mathbf{m})$ & Area $(\mathbf{h a})$ & Cover $(\%)$ of Island \\
\hline Net Gain $(\mathrm{m})$ & $>10$ & 1.01 & 0.04 \\
& $5.01-10$ & 5.10 & 0.18 \\
& $2.51-5$ & 10.70 & 0.39 \\
& $0.5-2.5$ & 779.01 & 28.15 \\
& Total & 802.01 & 28.98 \\
Net Loss (m) & $-0.5--2.5$ & 174.58 & 6.31 \\
& $-2.51--5$ & 52.90 & 1.91 \\
& $-5.01--10$ & 28.03 & 1.01 \\
& $<-10$ & 1.41 & 0.05 \\
& Total & 257.59 & 9.31 \\
\hline
\end{tabular}

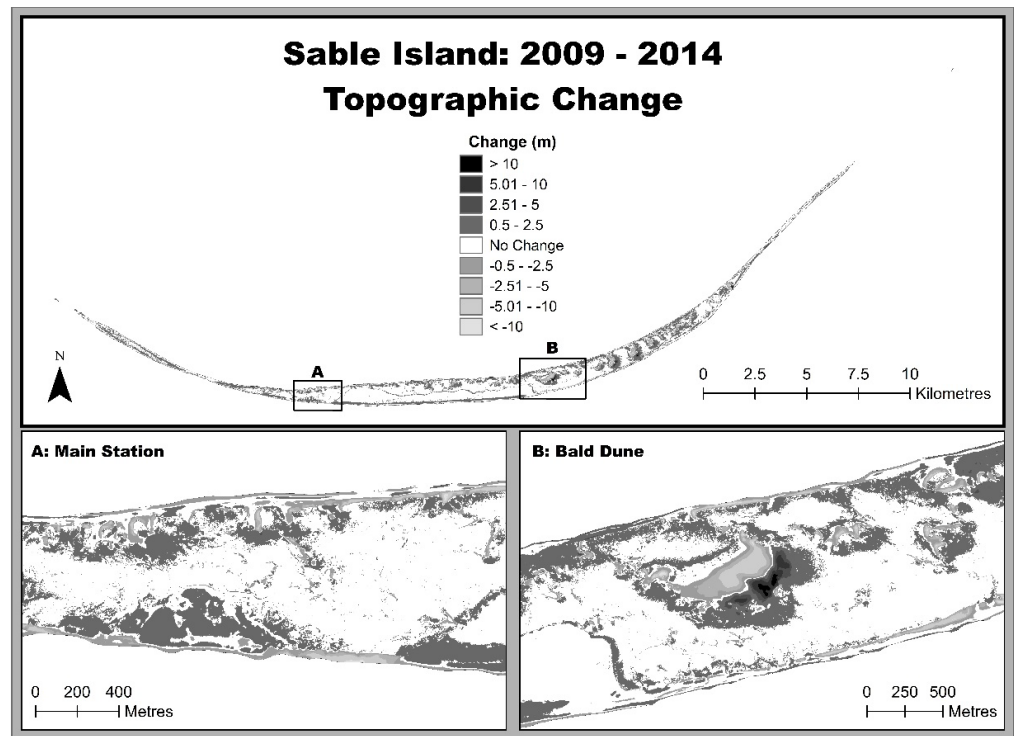

Fig $5 \quad 2009-2014$ topographic change of Sable Island.

Index layer (derived from the 2014 colour infrared imagery and shown in Fig 11) were used to interpret land cover classifications for the three years (Fig 12,13, and 14, respectively). The land cover for each survey year was further reclassified into early and late successional vegetation, sand, and water; differences were then computed and mapped (Fig 15 shows the results for 2009-2014). Table 5 shows the areal extent and proportion of each land cover class for each survey year. The extent of dense heath has decreased slightly while sparse heath 


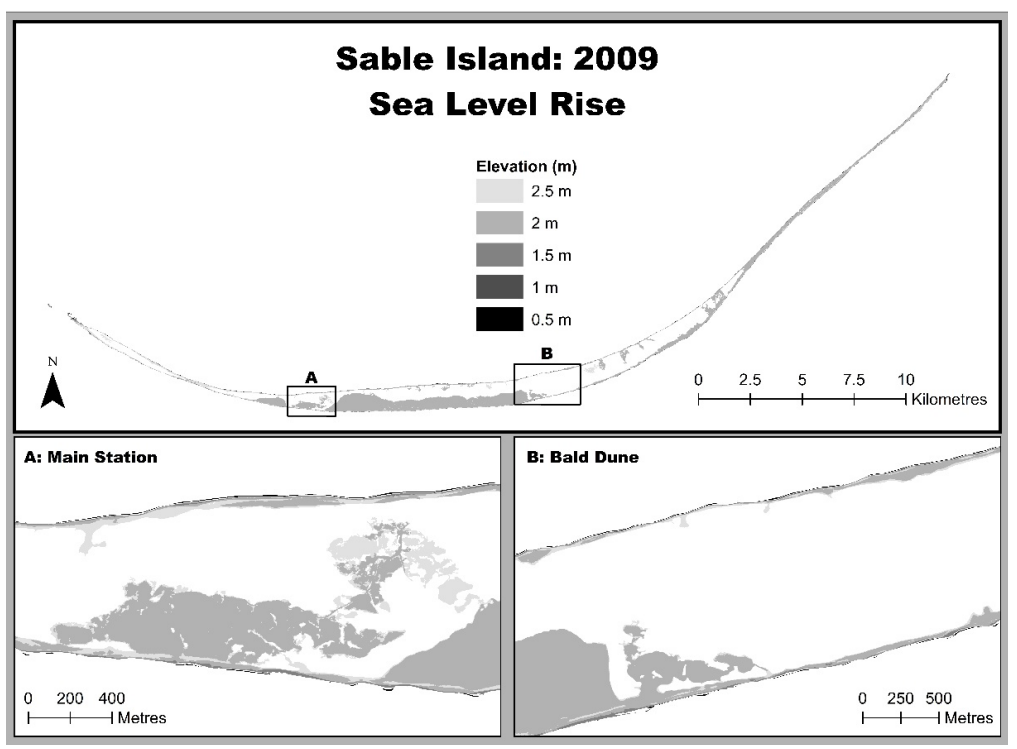

Fig 62009 potential sea level rise impacts on Sable Island.

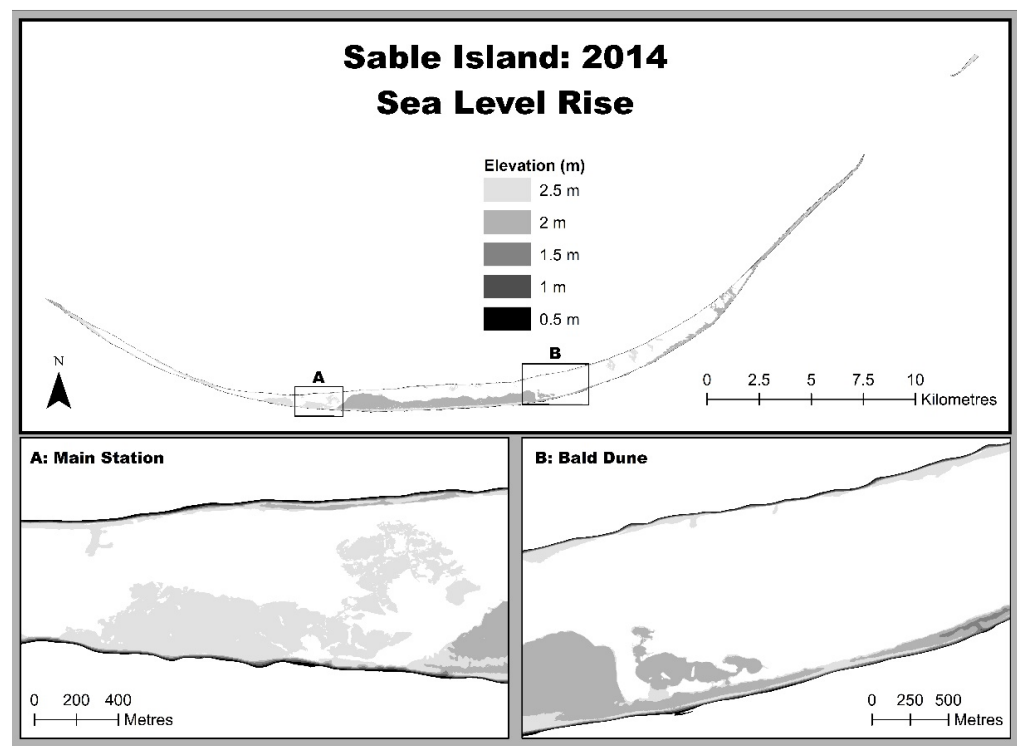

Fig 72014 potential sea level rise impacts on Sable Island. 


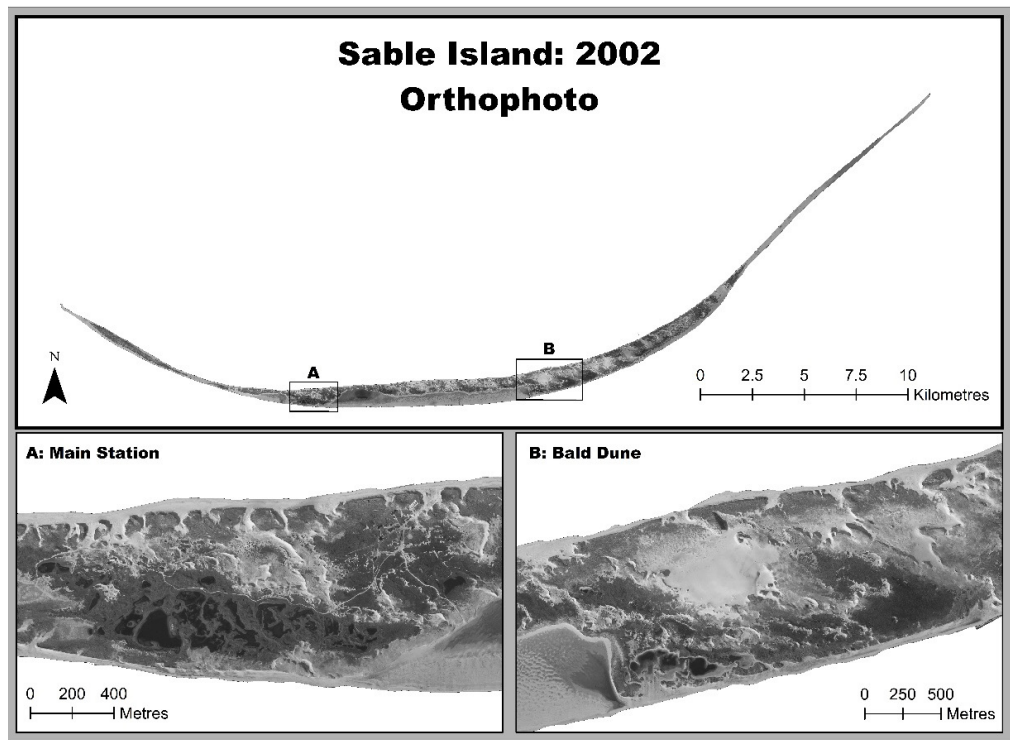

Fig 82002 orthophoto of Sable Island.

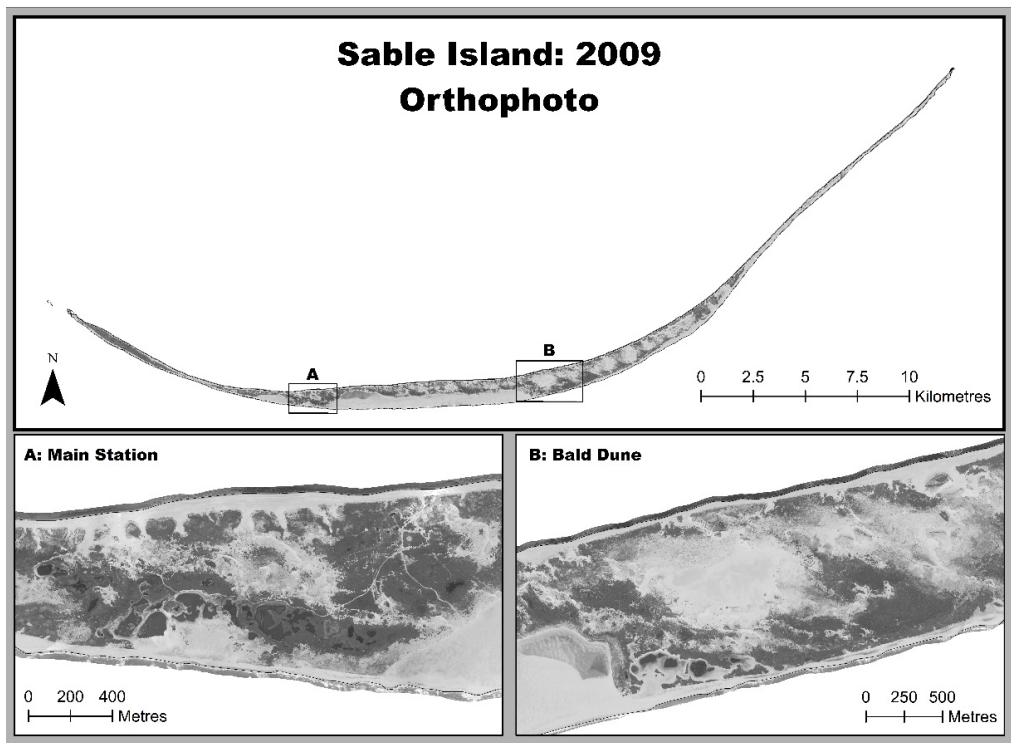

Fig 92009 orthophoto of Sable Island. 


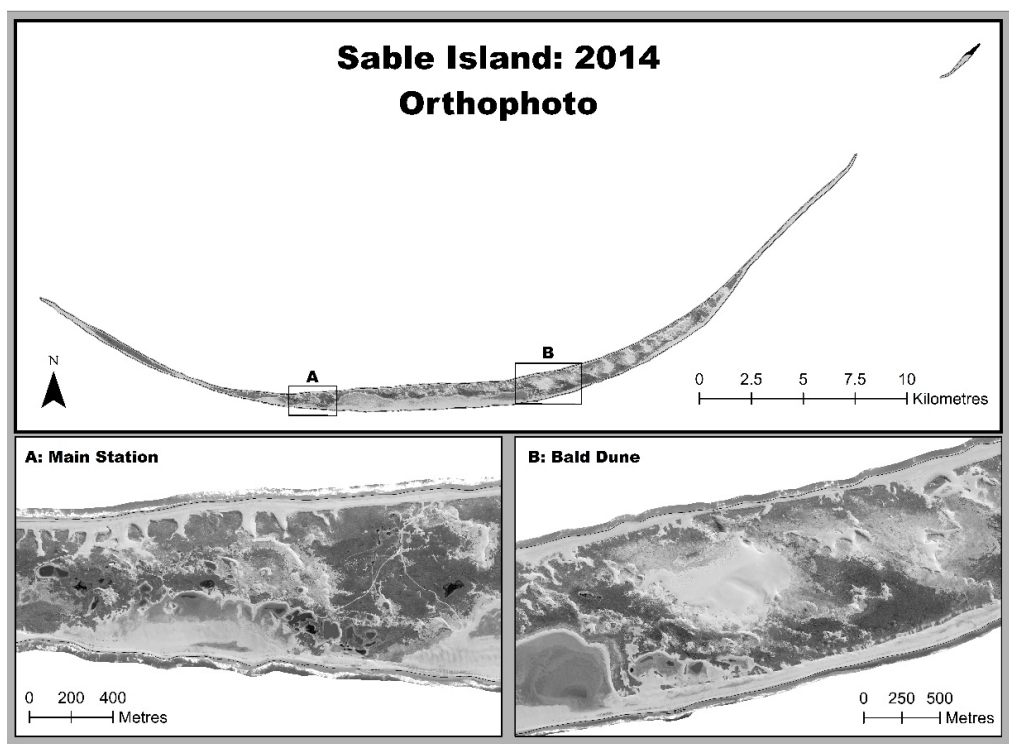

Fig 102014 orthophoto of Sable Island.

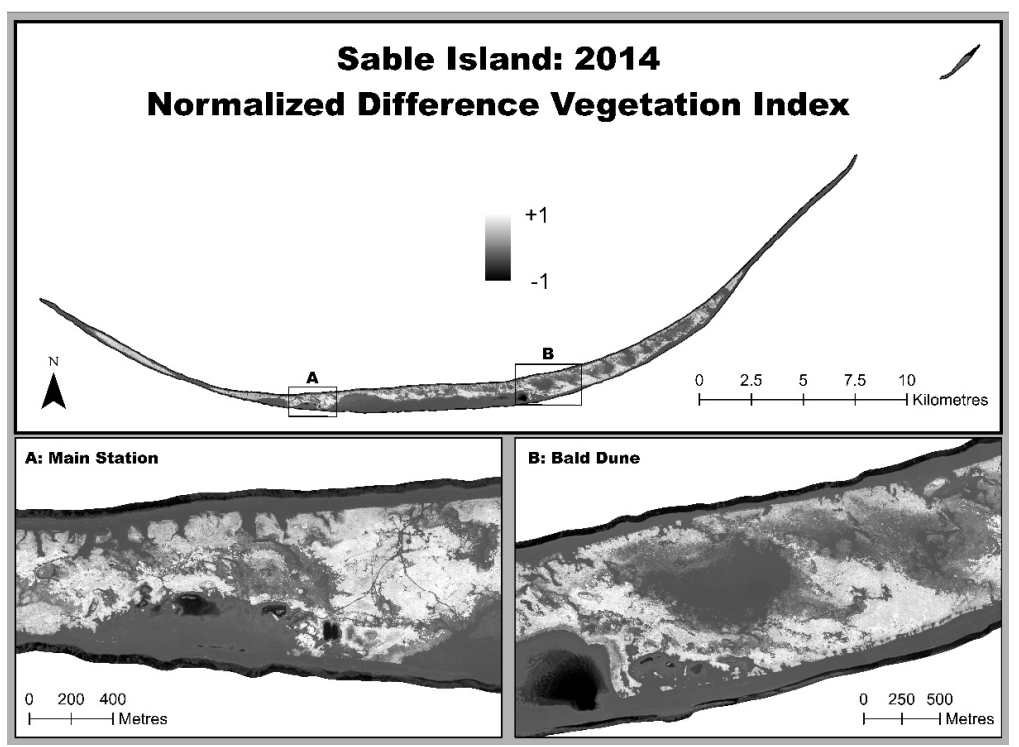

Fig 112014 Normalized Difference Vegetation Index of Sable Island. 


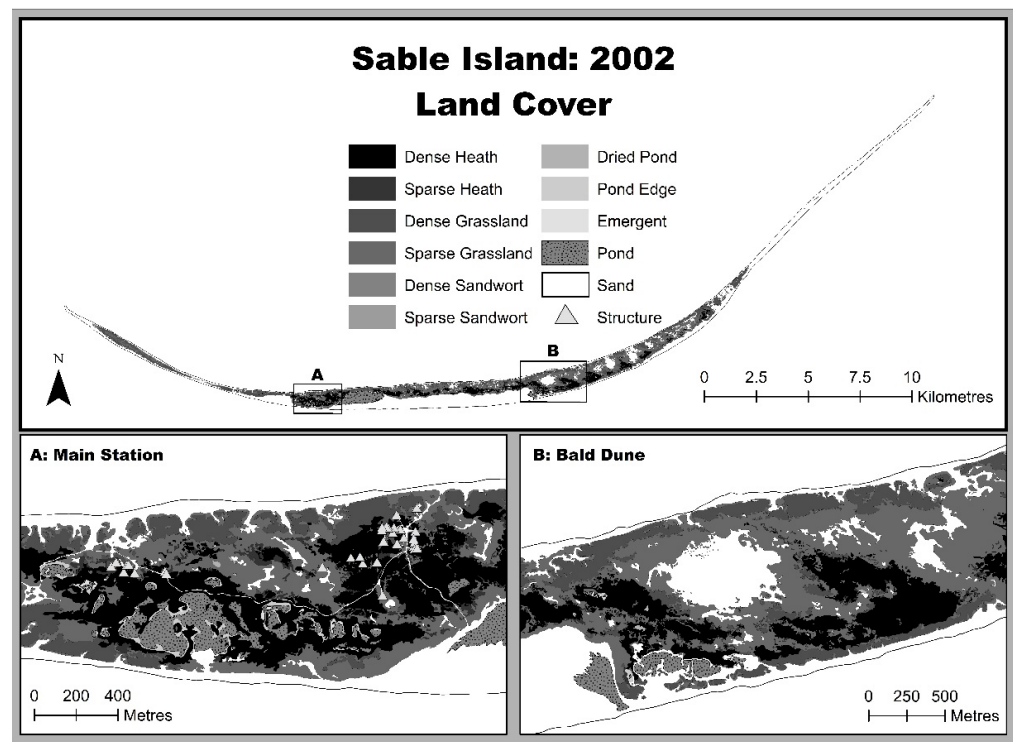

Fig 122002 land cover of Sable Island.

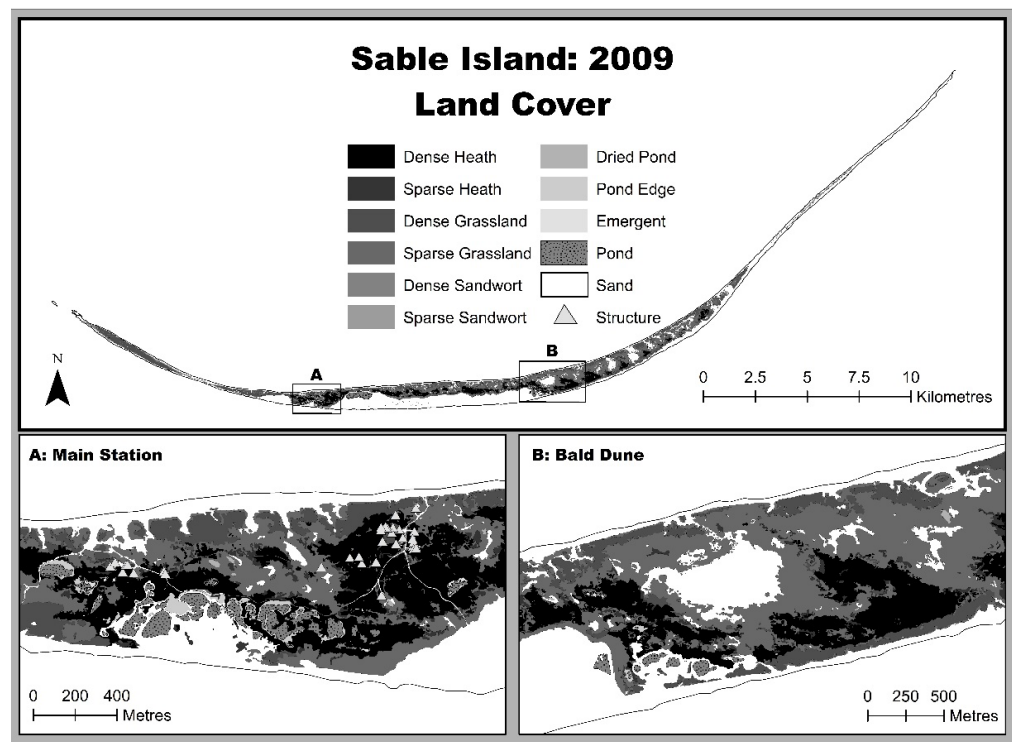

Fig 132009 land cover of Sable Island. 


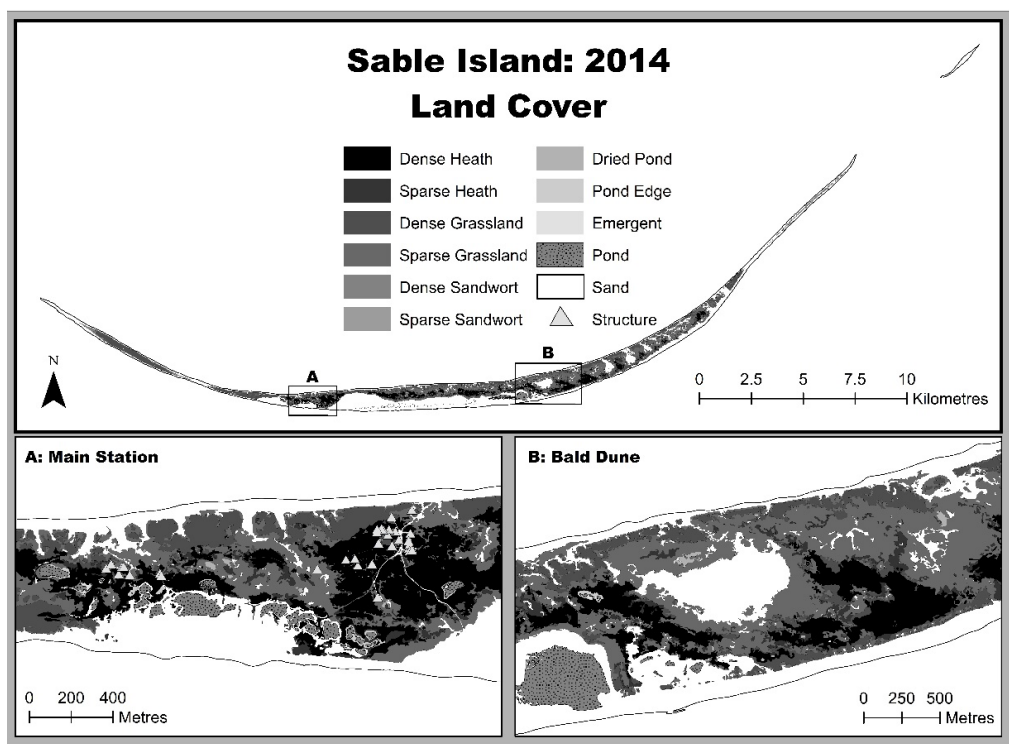

Fig 142014 land cover of Sable Island.

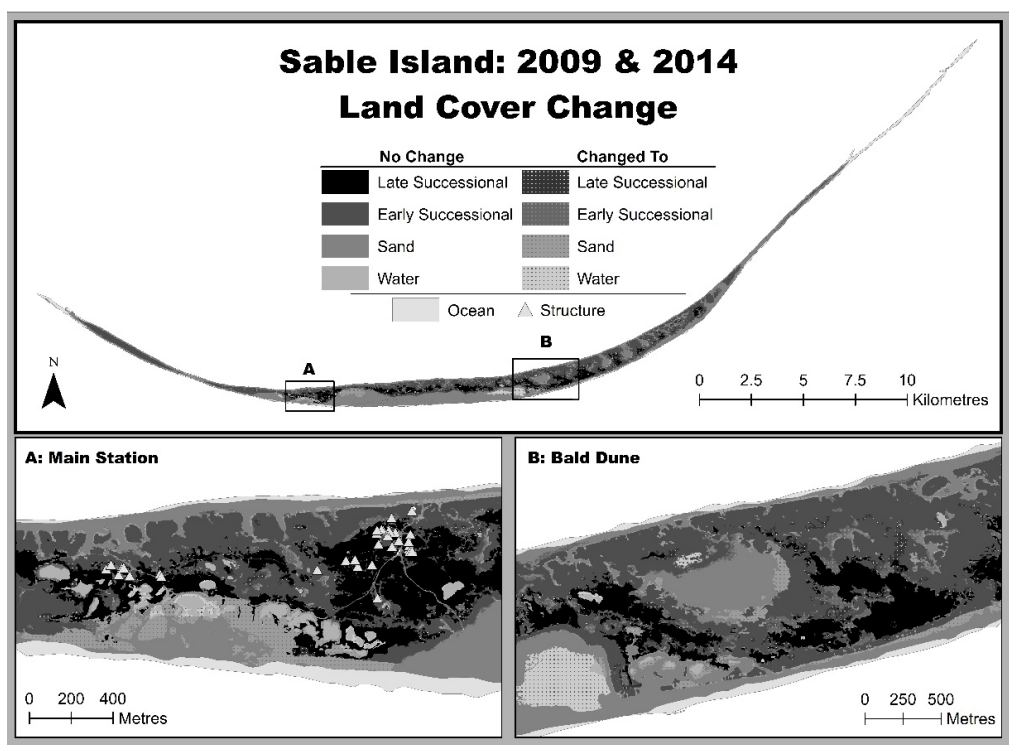

Fig 15 2009-2014 change in the major land cover types of Sable Island. 
Table 5 Areal extent of vegetation communities on Sable Island, 2002-2014.

\begin{tabular}{lrrrrrr}
\hline $\begin{array}{l}\text { Land } \\
\text { Cover }\end{array}$ & $\begin{array}{r}\text { Area } \\
\text { (ha) }\end{array}$ & $\begin{array}{c}\text { Area } \\
\text { (ha) }\end{array}$ & $\begin{array}{c}\text { Area } \\
\text { (ha) }\end{array}$ & $\begin{array}{c}\text { Cover } \\
(\mathbf{\%})\end{array}$ & $\begin{array}{c}\text { Cover } \\
(\%)\end{array}$ & $\begin{array}{c}\text { Cover } \\
(\%)\end{array}$ \\
\hline Dense heath & $\mathbf{2 0 0 2}$ & $\mathbf{2 0 0 9}$ & $\mathbf{2 0 1 4}$ & $\mathbf{2 0 0 2}$ & $\mathbf{2 0 0 9}$ & $\mathbf{2 0 1 4}$ \\
Sparse heath & 302.61 & 286.21 & 261.09 & 9.91 & 9.61 & 9.07 \\
Dense grassland & 26.24 & 43.86 & 73.09 & 0.86 & 1.47 & 2.54 \\
Sparse grassland & 393.55 & 385.64 & 427.20 & 12.88 & 12.94 & 14.84 \\
Dense sandwort & 701.15 & 720.23 & 646.80 & 22.95 & 24.18 & 22.47 \\
Sparse sandwort & 6.21 & 22.22 & 26.35 & 0.20 & 0.75 & 0.92 \\
Dried pond & 13.05 & 25.70 & 18.38 & 0.43 & 0.86 & 0.64 \\
Pond edge & 1.88 & 3.23 & 2.80 & 0.06 & 0.11 & 0.10 \\
Emergent & 7.34 & 6.12 & 4.67 & 0.24 & 0.21 & 0.16 \\
Pond & 0.95 & 1.89 & 0.90 & 0.03 & 0.06 & 0.03 \\
Sand & 126.56 & 50.87 & 47.53 & 4.14 & 1.71 & 1.65 \\
Structure & $1,474.77$ & $1,432.73$ & $1,369.47$ & 48.28 & 48.09 & 47.57 \\
Total vegetated & 0.47 & 0.49 & 0.49 & 0.02 & 0.02 & 0.02 \\
Total non-vegetated & $\mathbf{1 , 4 5 9 . 9 7}$ & $\mathbf{1 , 4 9 5 . 1 1}$ & $\mathbf{1 , 4 6 1 . 2 8}$ & $\mathbf{4 7 . 5 6}$ & $\mathbf{5 0 . 1 8}$ & $\mathbf{5 0 . 7 6}$ \\
Total early succession & $\mathbf{1 , 1 1 3 . 9 6}$ & $\mathbf{1 , 4 8 4 . 0 9}$ & $\mathbf{1 , 4 1 7 . 4 9}$ & $\mathbf{5 2 . 4 4}$ & $\mathbf{4 9 . 8 2}$ & $\mathbf{4 9 . 2 4}$ \\
Tota late succession & $\mathbf{3 2 8 . 8 5}$ & $\mathbf{3 3 0 . 0 7}$ & $\mathbf{1 , 1 1 8 . 7 3}$ & $\mathbf{3 3 4 . 4 6}$ & $\mathbf{3 8 . 7 3}$ & $\mathbf{3 8 . 8 7}$ \\
\hline
\end{tabular}

increased. Dense grassland has increased while sparse grassland has initially increased and then decreased. Overall, both sandwort classes have slightly increased.

The overall distribution of vegetation among succession classes is influenced by the topography and geomorphology of Sable Island. The influences of erosion and sand deposition vary spatially across the island and are strongest in exposed areas such as beaches, island tips, and in dune blow-out areas (Freedman et al. 2014). Erosion and deposition may be strong enough in these areas to preclude the establishment of new vegetation communities (Freedman et al.2014). In contrast, active deposition of sand is critical to the establishment of marram-dominated communities, so where erosion and deposition are active but less severe, open marram-dominated communities will be found (Freedman et al. 2014). Heath communities are confined to the most stable and protected inland mesic sites (Freedman et al. 2014). The availability of these sites is not likely to change dramatically over time unless there are large-scale changes in topography, thus the relatively consistent trends shown in total aerial coverage of vegetation communities.

Table 6 shows that although the overall area covered by early and late succession communities is relatively consistent, there are still changes occurring across the landscape. For example, from 2002 
Table 6 Change among major land cover classes from 2002 to 2014. Values in the table are area in hectares, followed by percent cover of the island in brackets.

\begin{tabular}{|c|c|c|c|c|c|}
\hline \multicolumn{6}{|c|}{2014} \\
\hline & & $\begin{array}{c}\text { Area (ha) } \\
\text { Late } \\
\text { Successsion } \\
\text { [\% cover] }\end{array}$ & $\begin{array}{l}\text { Area }(\text { ha) } \\
\text { Early } \\
\text { Succession } \\
{[\% \text { cover] }}\end{array}$ & $\begin{array}{c}\text { Area (ha) } \\
\text { Water } \\
{[\% \text { cover }]}\end{array}$ & $\begin{array}{c}\text { Area (ha) } \\
\text { Sand } \\
{[\% \text { cover] }}\end{array}$ \\
\hline \multirow{4}{*}{2002} & $\begin{array}{l}\text { Late } \\
\text { Succession }\end{array}$ & $\begin{array}{l}249.77 \\
{[7.89]}\end{array}$ & $\begin{array}{c}59.9 \\
{[1.89]}\end{array}$ & $\begin{array}{c}2.7 \\
{[0.09]}\end{array}$ & $\begin{array}{l}15.26 \\
{[0.48]}\end{array}$ \\
\hline & $\begin{array}{l}\text { Early } \\
\text { Succession }\end{array}$ & $\begin{array}{l}80.00 \\
{[2.53]}\end{array}$ & $\begin{array}{c}877.93 \\
{[27.73]}\end{array}$ & $\begin{array}{c}0.60 \\
{[0.02]}\end{array}$ & $\begin{array}{l}142.86 \\
{[4.51]}\end{array}$ \\
\hline & Water & $\begin{array}{c}2.16 \\
{[0.07]}\end{array}$ & $\begin{array}{c}1.24 \\
{[0.04]}\end{array}$ & $\begin{array}{l}18.54 \\
{[0.59]}\end{array}$ & $\begin{array}{l}114.75 \\
{[3.62]}\end{array}$ \\
\hline & Sand & $\begin{array}{c}2.24 \\
{[0.07]}\end{array}$ & $\begin{array}{l}179.53 \\
{[5.67]}\end{array}$ & $\begin{array}{l}34.04 \\
{[1.07]}\end{array}$ & $\begin{array}{l}985.20 \\
{[31.12]}\end{array}$ \\
\hline
\end{tabular}

to 2014,80 ha of vegetation cover transitioned from early to late succession vegetation classes and approximately 60 ha of vegetation regressed from late to early succession vegetation classes. Additionally, 180 ha transitioned from sand to early succession vegetation and 143 ha of early succession vegetation eroded or was buried through deposition to become classified as sand.

The total amount of vegetated terrain currently accounts for approximately $50 \%$ of the surface of Sable Island (Table 5) with the major vegetation communities being grassland $(\sim 38 \%)$ and heath $(\sim 11 \%)$. The total vegetated area of Sable Island has remained stable (between 1459.97 ha and 1495.11 ha) between 2002 and 2014 (Table 5). Earlier estimates from historic aerial photos showed the total vegetated area of Sable Island to be slightly increasing over time, from 1279 ha in 1963 to 1525 ha in 1996 (Freedman 2001); however, Freedman et al. (2014) notes that this estimated increase in vegetated area is likely confounded to some degree by differences in interpretability among sets of aerial photos, due to varying scales, seasons, colour and textural quality.

Within this context, it is important to note that there may be some uncertainty introduced in this assessment through the use of estimates from interpretation of historic aerial photos. Historic data from these photos may be confounded by differences in analytical methods and in resolution and interpretability among sets of air photos (Freedman et al.2014). For example, the 1981 aerial photos were faded and the 
Table 72014 Data validations results.

\begin{tabular}{|c|c|c|c|c|}
\hline $\begin{array}{l}\text { Survey } \\
\text { Year }\end{array}$ & $\begin{array}{c}\text { RTK GP vs } \\
\text { DSM } \\
\text { Height } \\
\text { Match }(\%)\end{array}$ & $\begin{array}{c}\text { Plot vs } \\
\text { UAV } \\
\text { Landcover } \\
\text { Match (\%) }\end{array}$ & $\begin{array}{c}\text { Plot vs } \\
\text { Island } \\
\text { Landcover } \\
\text { Match (\%) }\end{array}$ & $\begin{array}{c}\text { UAV vs } \\
\text { Island } \\
\text { Landcover } \\
\text { Match (\%) }\end{array}$ \\
\hline 2014 & 94.50 & 81.13 & 81.82 & 92.45 \\
\hline
\end{tabular}

interpreter reported difficulties in distinguishing heath from grassland communities (Freedman 2001). The 1972 aerial photos were taken in late May, which is early in the growing season for Sable Island. Because of this, the vegetation was not well developed and accurate interpretation of sparse grassland and sandwort was affected (Freedman 2001). Despite this uncertainty, these historic data are important because they provide early estimates of the aerial coverage of vegetation communities; however, it is important to recognize that there may be some error associated with the quality of this imagery, effecting comparisons to later surveys with much higher resolution digital imagery.

To assess survey errors the AGRG implemented validation efforts for both the topography and land cover results (Table 7). For example, all validation measures conducted for the 2014 survey indicated that there was a close match. No less than $94.5 \%$ of the RTK GPS heights used were within $20 \mathrm{~cm}$ of the DSM heights (the expected error tolerance of the LiDAR system used), and $76.61 \%$ were within $10 \mathrm{~cm}$. The land cover validation measures were all greater than $80 \%$, which bodes well for the integrity of the results; however, there is always room for improvement. The $2 \mathrm{~m}^{2}$ vegetation plot measures ( $\left.81 \%\right)$ were hampered by the fact that the manual interpretation of the land cover tended to group small land cover variations into larger vegetation patches. An automated classification would have done a better job of identifying the small variations in land cover across the island.

As noted above, the timing of the surveys can also impact the land cover results. Although all aerial surveys between 1963 and 2014 were conducted between May and October, slight differences in the timing of the surveys relative to the growing season on Sable Island may have an influence on the total areal extent of various plant communities. In the future, LiDAR and digital aerial photographic surveys will be conducted in August or September every five years as part of Parks Canada's Ecological Integrity monitoring program for Sable 
Island to track changes in key topographic features and land cover classes on the island.

The results of this study are being used by Parks Canada in their Ecological Integrity (EI) assessment of the island. Interim EI thresholds have been identified and will be reviewed and refined as more information is available related to temporal variability in aerial extent of vegetation communities. The existing frequency of land cover mapping may be too coarse to correctly interpret the temporally dynamic nature of vegetation succession and dune change on Sable Island. As a result, a temporally dense set of satellite imagery will be examined to better determine inter-annual variability (Parks Canada 2015). This could be done through examining available satellite images from the last five years or through acquiring annual imagery for the next several years. The approach of setting thresholds based on the range of variability in existing land cover data seems appropriate given that the overall aerial extent of land cover classes is expected to remain fairly consistent over time, as demonstrated in this assessment.

In the future, LiDAR and digital aerial photographic surveys will be conducted every five years and the landscape change index will be re-examined every ten years to assess status and trends in vegetation communities and erosion processes on Sable Island. Additionally, as identified in this assessment as well as in Freedman et al. (2014), the following research priorities are required to better understand the condition and trends in landscape change on Sable Island:

- Development and testing of an automated classification process to increase efficiency and potential accuracy of the process of delineating land cover classes on Sable Island.

- Enhanced understanding of the causes and processes of dune erosion and development on Sable Island, which will contribute to the development and interpretation of dune blow-outs, for incorporation in the landscape change index along with measures of vegetation cover.

- Identification of inter-annual variability in early and late succession vegetation communities and dune blow-outs based on examination of annual satellite imagery, which will inform the development of thresholds for interpreting landscape change on Sable Island. 


\section{CONCLUSIONS}

The work outlined in this paper has provided fieldwork information in four databases: one with ground target data and RTK GPS locations associated with land cover types; two associated with land cover plot photos; one with UAV images. The high degree of spatial referencing and the high resolution photos not only validate current land cover types, but they can also provide valuable information for future work, if different cover types are detected (i.e., increasing invasive species such as knotweeds). The photos provide visual evidence of presence/absence in spatially referenced plots surveyed in 2010 and 2014. In addition, valuable topographic products were created from the LiDAR-derived DSM data that include: island coastlines (defined by the 0 m contour); volumes and elevations (with associated net gain and net loss calculations); potential flooding impacts of sea level rise. Orthophoto-derived land cover products were also created and include: NDVI (greenness) from the CIR orthophoto; land cover classifications; successional cover type classifications (with associated net gain and net loss calculations); accurate pond delineations (including the one from 2014 which was a summer with very low water levels).

These products give the island a surface representation as well as a 3-D representation; going forward, they can address specific areas of concern with a high level of confidence (as shown by Table 7). These products will assist Parks Canada management in implementing Ecological Integrity measures and determining appropriate thresholds. They also have the potential to assist other researchers by combining these data and derived products with other observations to increase the understanding of how the terrestrial processes interact to provide habitat. Important in this will be the condition of the freshwater lens, the rate of change of sand movement and geomorphic processes, the quality of habitat to maintain species existing on the island, as well as offshore coastal processes. After all, the terrestrial habitats are in the larger picture influenced by weather events, currents, and additional shoreline hydrographic information.

Acknowledgements This paper presents a body of work that has taken place over 14 years. Over these years many people have provided valuable assistance. The lead author would especially like to thank: Paul Illsley, Trevor Milne, and Tim Kearns (COGS); Allison Muise and Suzanne Monette (AGRG); Jonathan Sheppard, Sally O'Grady, 
and Chris McCarthy (Parks Canada); Nell den Heyer, Jim McMillian, and Don Bowen (Bedford Institute of Oceanography); Derek Fenton (Environment Canada); Rick Welsford (Sable Island Preservation Trust); Gerry Forbes, Aaron Carpenter, and Zoe Lucas for on-island support; and the many COGS students who have worked diligently and made significant contributions to our ongoing Sable Island efforts. The Sable Island Preservation Trust (SIPT), Canadian Wildlife Service (CWS), and Parks Canada have all financially contributed to this work over the years and for this we are indeed grateful.

\section{REFERENCES}

Applied Geomatics Research Group. (2011). Sable Island, Nova Scotia 2009 topography and land cover atlas. Nova Scotia Community College, Middleton, NS.

Applied Geomatics Research Group. (2015). Sable Island, Nova Scotia 2014 topography and land cover atlas. Nova Scotia Community College, Middleton, NS.

Bond, J. (2016). Enabling high-precision, position monitoring of Sable Island through the Nova Scotia coordinate referencing system. NSIS Proceedings 48(2):265-284.

Byrne, M., Freedman, B., \& Colville, D. (2014). The geology of Sable Island and evolution of the Sable Island bank. In: Freedman, B. (ed). An ecological and biodiversity assessment of Sable Island. Report prepared for Parks Canada, Halifax, NS.

Catling,P.M.,Freedman, B., \& Lucas,Z. (1984). The vegetation and phytogeography of Sable Island, Nova Scotia. NSIS Proceedings 34:181-247

CWS. (1998). Towards a conservation strategy for Sable Island. Environment Canada, Canadian Wildlife Service, Atlantic Region, Sackville, NB.

Freedman, B. (2001). Air photo assessment of changes in plant cover on Sable Island, Nova Scotia. Report produced for Canadian Wildlife Service, Atlantic Region, Sackville, NB.

Freedman, B. (2014). An ecological and biodiversity assessment of Sable Island. Report prepared for Parks Canada, Halifax, NS.

Freedman, B., Catling, P.M., Lucas, Z., Colville, D., \& Lacoul, P. (2014). Plant communities of Sable Island. In: Freedman, B. (ed). An ecological and biodiversity assessment of Sable Island. Report prepared for Parks Canada, Halifax, NS.

Freedman, B., Lucas, Z., Lacoul, P., \& Catling,P. (2014). Ponds on Sable Island. In: Freedman, B. (ed). An ecological and biodiversity assessment of Sable Island. Report prepared for Parks Canada, Halifax, NS.

Muise, A.M. (2012). Object-based land-cover classification of Sable Island, Nova Scotia. MSc, Applied Geomatics thesis. Acadia University, Wolfville, NS. 
Parks Canada Agency. (2011). Consolidated guidelines for ecological integrity monitoring in Canada's national parks. Parks Canada, Gatineau, QC. Parks Canada Agency. (2015). Ecological integrity monitoring review of Sable Island National Park Reserve. Monitoring and Ecological Information Division, Natural Resource Conservation Branch, Parks Canada, Gatineau, QC.

Stobo, W.T., \& McLaren, I.A. (1975). The Ipswich sparrow. NSIS Proceedings 27(2):1-105.

Welsh, D.A. (1975). Population, behavioural, and grazing ecology of the horses of Sable Island, Nova Scotia. PhD thesis, Department of Biology, Dalhousie University, Halifax, NS. 
